\title{
NEUROPATÍA ÓPTICA AUTOINMUNE RECIDIVANTE BILATERAL EN LA INFANCIA
}

\author{
BILATERAL RECURRENT AUTOIMMUNE OPTICAL \\ NEUROPATHY IN CHILDHOOD
}

\author{
GARCÍA-GÓMEZ $\mathrm{PJ}^{1}$, BELZUNCE A ${ }^{1}$, SALINAS ALAMÁN A ${ }^{2}$, HERAS $\mathrm{H}^{1}$, SÁDABA LM ${ }^{2}$
}

\begin{abstract}
RESUMEN
Caso clínico: Niña de 10 años, que tras gastroenteritis por Yersinia debuta con neuritis óptica en ojo izquierdo. No recibe tratamiento y evoluciona a atrofia óptica. A los 6 meses presentó un episodio en el ojo contralateral, instaurándose tratamiento corticoideo. Durante su disminución progresiva sufre tres recaídas. Se decide instaurar tratamiento con inmunosupresores, manteniéndose estable desde entonces sin efectos secundarios.

Discusión: Tras descartar las múltiples causas de neuritis óptica bilateral recidivante en una niña, se concluye que la etiología era autoinmune. Valorando los beneficios y riesgos del tratamiento con inmunosupresores creemos que permiten el control de la enfermedad y el ahorro corticoideo.
\end{abstract}

Palabras clave: Neuritis óptica autoinmune, neuritis óptica postinfecciosa, neuritis óptica bilateral, neuritis óptica infancia, Azatioprina.

\begin{abstract}
Clinical case: A ten year-old girl, after a Yersinia gastroenteritis, developed an optic neuritis in the left eye. She was not treated and resulted ultimately in optic atrophy on the affected side. Six months later a similar episode occurred in the contralateral eye. On this occasion corticosteroid therapy was given. During this therapy the neuritis diminished; however the patient had three relapses, so it was decided to give her immunosuppressive treatment with azathioprine and continue this indefinitely.

Discussion: After considering the differential diagnoses of bilateral recurrent optical neuritis in childhood, we concluded that it was most likely to have an autoimmune basis. After considering the benefits and risks of the long-term treatment, we believe immunosuppressive therapy is most useful in controlling the disease allowing corticosteroid therapy to be reduced (Arch Soc Esp Oftalmol 2006; 81: 607-610).
\end{abstract}

Key words: Autoimmune optic neuritis, post-infectious optic neuritis, bilateral optic neuritis, childhood optic neuritis, Azathioprine.

Recibido: 7/9/05. Aceptado: 21/9/06.

Departamento de Oftalmología. Clínica Universitaria de Navarra. Universidad de Navarra. Pamplona (Navarra). España.

1 Licenciado en Medicina.

2 Doctor en Medicina.

Comunicación presentada en el Congreso Nacional de Residentes de Oftalmología (Marbella 2004).

Correspondencia:

Pío Jesús García Gómez

Departamento de Oftalmología. Clínica Universitaria de Navarra

Avda. Pío XII, 36

31008 Pamplona (Navarra)

España

E-mail: piojesusgg@yahoo.es 


\section{INTRODUCCIÓN}

La neuritis óptica más frecuente en niños es la postinfecciosa, siendo bilateral y teniendo un pronóstico visual excelente (1). Sin embargo, ante un cuadro bilateral y prolongado, con mayor repercusión funcional, es necesario excluir otras causas de afectación del nervio óptico. Una de ellas, descartadas las causas desmielinizantes, metabólicas, tóxico-carenciales y compresivas, es la etiología autoinmune. La neuropatía óptica autoinmune puede presentarse aislada, su curso es recidivante y su origen incierto. En su tratamiento juegan un papel fundamental los corticoides. En los niños, los efectos secundarios de los corticoides en su uso prolongado, especialmente, sobre la curva de crecimiento, obliga al uso de inmunosupresores.

Se presenta el caso de una niña de 10 años con una neuropatía óptica bilateral autoinmune, de curso recidivante y severo. Se plantea la estrategia diagnóstica, el uso de azatioprina para ahorrar corticoides y la hipótesis de una bacteria Gram negativa, Yersinia enterocolítica, como inductora de la respuesta inmunológica sobre el nervio óptico.

\section{CASO CLÍNICO}

Niña de 10 años sin antecedentes de interés, que dos semanas después de una gastroenteritis por Yersinia refiere disminución de la agudeza visual (AV) y dolor a la movilización con ojo izquierdo (OI). Diagnosticada de neuritis óptica izquierda. Se realizó una resonancia magnética nuclear cerebral (RMNC) que fue normal. No prescribiéndose tratamiento.

Seis meses después, presentó un cuadro de pérdida visual del ojo derecho (OD), que fue diagnosticada de papilitis. La RMNC mostraba una lesión inflamatoria en el nervio óptico (hiperintensidad de señal en T2). Fue tratada con pulsos intravenosos de metilprednisolona (1 gramo/día durante 3 días) y posteriormente con corticoides orales comenzando con $1 \mathrm{mg} / \mathrm{kg} /$ día durante 1 semana y disminución progresiva.

Acudió por primera vez a nuestra consulta al mes del diagnóstico de la papilitis en el OD. Presentaba una AV corregida en el OD de 0,8; y en el OI de movimientos de mano, defecto pupilar aferente relativo en OI, discromatopsia rojo-verde en OD, acromatopsia en OI, y menor sensibilidad al con- traste. La funduscopia mostró una papilitis en el OD (fig. 1A); y atrofia papilar en el OI (fig. 1B). El campo visual $(\mathrm{CV})$ del OD era normal, existiendo un escotoma difuso absoluto en el OI para el estímulo III de Humprey. La tomografía de coherencia óptica (OCT) reveló una pérdida difusa en la capa de fibras del OI y focal en el OD (fig. 2A).

Se completó el estudio con hemograma, VSG, coagulación, bioquímica básica, serologías víricas séricas (citomegalovirus, herpes, virus de inmunodeficiencia humana, sarampión, parotiditis, Ebstein Barr, Herpes 6), pruebas treponémicas (FTA-Abs), no treponémicas (VDRL), serologías de Borrelia y Bartonella, niveles de plomo, vitamina B12 que fueron negativas. Se realizó un análisis genético del DNA mitocondrial no encontrándose mutaciones propias de la enfermedad de Leber. La punción

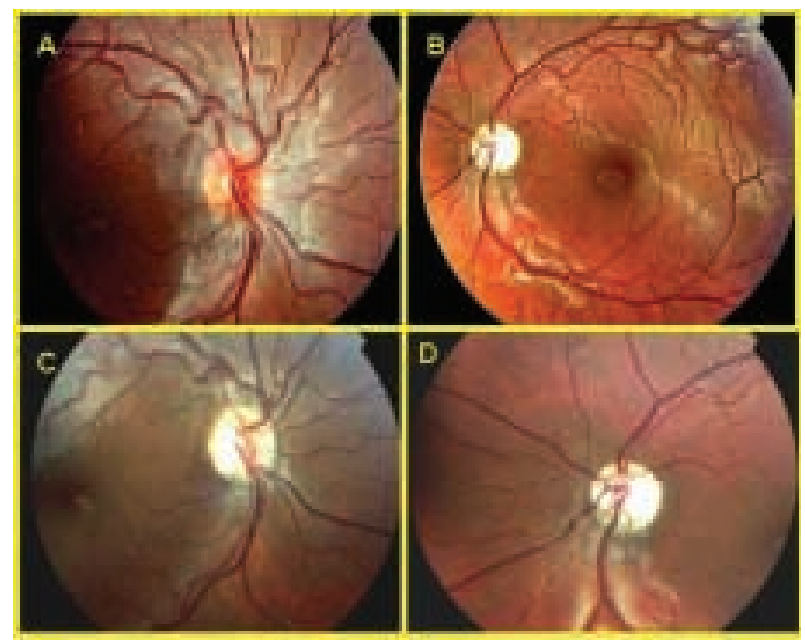

Fig. 1: Imagen funduscópica de ambos ojos. 1A y 1B: Corresponden a la primera consulta de la paciente en nuestro departamento. IC y 1D: Imagen correspondiente con la tercera recaída. Se observa la evolución a atrofia óptica del $O D$.

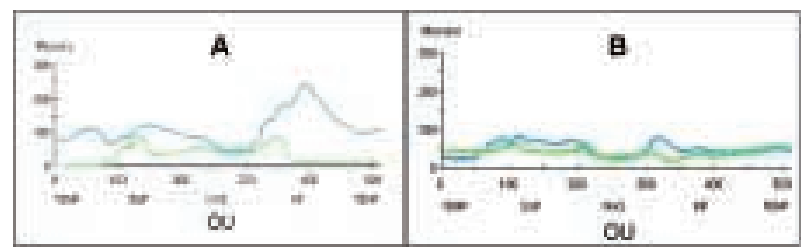

Fig. 2: Imagen de OCT de capa de fibras de ambos ojos: OD color azul. OI color verde. 2A: Primera consulta de la paciente a nuestro servicio. 2B: Durante la tercera recaída. Progresiva pérdida de fibras del ojo derecho. 
lumbar reflejó dos bandas oligoclonales. El electrocardiograma fue normal y los potenciales evocados visuales alterados. Los anticuerpos antinucleares (ANA) y antifosfolípido fueron positivos.

Tras mantenerse sin cambios durante los 6 meses de tratamiento corticoideo, sufrió dos recaídas en 14 meses y se decidió añadir Azatioprina (50 $\mathrm{mg}$ /día el primer mes, aumentando después hasta $100 \mathrm{mg} /$ día. Control mediante estudio enzimático TPMT). Al año, sufrió una nueva recaída en el OD disminuyendo la AV hasta 0,12 , observándose una alteración del CV (fig. 3), una atrofia óptica en la funduscopia (fig. 1C) y en la OCT una pérdida generalizada de la capa de fibras en ambos ojos (fig. 2B).

Desde entonces, tras 24 meses, la paciente presenta una AV estable $(0,1)$, manteniendo el tratamiento con azatioprina a dosis máxima de 3 $\mathrm{mg} / \mathrm{kg} /$ día.

\section{DISCUSIÓN}

Se trata de un caso de una neuropatía óptica bilateral recidivante con evolución a atrofia óptica en una niña tras una gastroenteritis por Yersinia. Según el curso clínico (1) (bilateral y recidivante) y la funduscopia (edema de papila), se debieron descartar causas inflamatorias (conectivopatías, postvíricas o postvacunales), infecciosas, desmielinizantes (RMNC y múltiples serologías víricas y bacterianas resultaron negativas) y la neuropatía óptica de Leber (análisis normal de mutaciones primarias del DNA mitocondrial). Se excluyeron otras causas como leucemia, lupus eritematoso diseminado, tóxicas, metabólicas y heredodegenerativas.

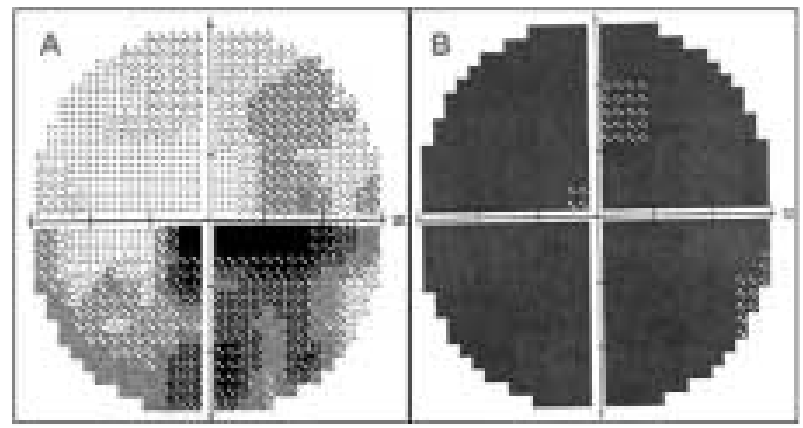

Fig. 3: Imagen de un campo visual 30-2 de la paciente tras la tercera recaída: 3A: Escotoma centrocecal del OD. 3B: Escotoma difuso absoluto del OI.
A la vista de los resultados anteriores, cabía la posibilidad de estar ante una neuritis óptica postinfecciosa por Yersinia (a favor: aparición 1-3 semanas tras la infección, bilateralidad, edad, existencia de 2 bandas oligoclonales en LCR y neuroimagen negativa. En contra: mala recuperación visual y ausencia de anticuerpos en suero o LCR, los cuales se detectan hasta 8 meses después del inicio del cuadro debido a una respuesta humoral persistente tipo IgA. No se solicitaron HSP60, o proteínas de choque térmico, las cuales son blanco para la respuesta inmune en múltiples enfermedades inflamatorias) o una neuritis óptica autoinmune desmielinizante donde la infección por Yersinia sería el factor desencadenante (a favor: dependencia corticoidea, positividad de los ANA, hiperintensidad de señal en T2 del nervio óptico y ausencia de datos de enfermedad desmielinizante en la RMNC).

Actualmente se conoce que la Yersinia está implicada en espondiloartropatías infecciosas, actuando como agente infeccioso (2) frente al cual el organismo produce una respuesta inmunológica. En este caso, la Yersinia podría actuar como mecanismo activador de la respuesta inmunológica contra el nervio óptico produciendo una desmielinización del mismo (la paciente no presenta ninguna otra sintomatología autoinmune).

Para la confirmación del cuadro autoinmune, se podría realizar una biopsia cutánea con inmunofluorescencia (3) aunque al no presentar la paciente en este caso acidosis láctica la prueba perdía capacidad diagnóstica.

En el seguimiento es interesante la OCT para confirmar el daño en la capa de fibras nerviosas en pacientes donde la campimetría convencional pierde fiabilidad por la escasa colaboración del niño.

En las neuropatías ópticas autoinmunes, donde la respuesta a corticoides se ve empobrecida por las recurrencias al disminuir la dosis, está indicado el tratamiento con corticoides orales durante tiempo prolongado (4). El tratamiento inmunosupresor tiene la finalidad de disminuir las dosis de corticoides en estos cuadros crónicos y recurrentes. En la revisión de Myers (5), el 79\% de los pacientes mostraron beneficio clínico (AV estable y ausencia de efectos secundarios) con una terapia ahorradora de corticoides. Para este ahorro utilizaron en su lugar azatioprina, debido a su menor incidencia de efectos secundarios y a su utilización en enfermedades donde la activación de la inmunidad humoral y la posterior desmielinización del nervio óptico pare- 
cen jugar un papel relevante (neuromielitis óptica de Devic y neuropatías ópticas autoinmunes).

Basándonos en estos estudios, y teniendo en cuenta el curso crónico y progresivo de nuestro caso, se decidió iniciar tratamiento con Azatioprina (Imurel ${ }^{\circledR}$ ) a dosis iniciales de $50 \mathrm{mg} /$ día el primer mes y ante la insuficiente respuesta y ausencia de efectos secundarios, con control de TPMT previo, se subió la dosis hasta los $3 \mathrm{mg} / \mathrm{kg} / \mathrm{día}$ $(150 \mathrm{mg})$ que fue bien tolerada y detuvo las recidivas del cuadro.

\section{AGRADECIMIENTOS}

Los autores de este trabajo agradecen la ayuda técnica prestada por Amaia Zaratiegui.

\section{BIBLIOGRAFÍA}

1. Arruga Ginebreda J, Sánchez Dalmau B. Neuropatías ópticas: diagnóstico y tratamiento. Madrid: Sociedad Española de Oftalmología; 2002: 293-295.

2. Ifergane $G$, Bersudsky $M$, Kachko L, Wirguin I. Induction of conduction block by Campylobacter jejuni lipopolysaccharides and focal neural insult. J Neurol Sci 2003; 213 : 11-14.

3. Riedel P, Wall M, Grey A, Cannon T, Folberg R, Thompson HS. Autoimmune optic neuropathy. Arch Ophthalmol 1998; 116: 1121-1124.

4. Arruga Ginebreda J. ¿Qué hemos aprendido del estudio multicéntrico sobre el tratamiento de las neuritis ópticas con corticoides? Arch Soc Esp Oftalmol 2001; 76: 391392.

5. Myers TD, Smith JR, Wertheim MS, Egan RA, Shults WT, Rosembaum JT. Use of corticoseroid sparing systemic inmunosuppression for treatment of corticosteroid dependent optic neuritis not associated with demyelinating disease. Br J Ophthalmol 2004; 88: 673-680. 